\title{
ANALISIS KESUBURAN TANAH LAHAN PERTANIAN TANAMAN PADI DI NAGARI TALANG BABUNGO KECAMATAN HILIRAN GUMANTI KABUPATEN SOLOK
}

\author{
Ezik Firdaus ${ }^{1}$, Helfia Edial ${ }^{2}$, Ratna Wilis ${ }^{2}$ \\ Program Studi Geografi \\ Fakultas Ilmu Sosial Universitas Negeri Padang \\ Email : zikryalamsyah@yahoo.co.id
}

\begin{abstract}
ABSTRAK
Penelitian ini bertujuan: (1) Mengetahui tingkat kesuburan tanah untuk lahan pertanian tanaman padi di tinjau dari sifat fisik tanah (tekstur, kedalaman tanah dan permeabilitas) dan kimia tanah ( $\mathrm{pH}$ tanah, C-Organik, KTK, KB, $\mathrm{P}_{2} \mathrm{O}_{5}, \mathrm{~K}_{2} \mathrm{O}$ ) di Nagari Talang Babungo, Kecamatan Hiliran Gumanti Kabupaten Solok, (2) Mengetahui tingkat kesesuaian lahan untuk pertanian tanaman padi di Nagari Talang Babungo, Kecamatan Hiliran Gumanti

Metode yang digunakan dalam penelitian ini adalah metode survei dengan satuan pemetaan yang digunakan adalah satuan lahan melalui overlay peta satuan bentuklahan dengan peta lereng, peta geologi, peta tanah, dan peta penggunaan lahan. Pengambilan sampel dengan metode sampel bertingkat (Stratified Sampling), dengan analisis data menggunakan metode matching dan metode kombinasi.

Hasil penelitian ini: (1) Tingkat kesuburan tanah pertanian tanaman padi pada daerah penelitian tergolong rendah $(\mathrm{R})$ dengan karakteristik lahan pada daerah penelitian antara lain: tekstur tanah sedang, agak halus sampai halus, kedalaman tanah yaitu $23->50 \mathrm{~cm}$, permeabilitas tanah yaitu $0,20 \mathrm{~cm} / \mathrm{jam}-27,35 \mathrm{~cm} / \mathrm{jam}$, KTK tanah $9,448 \mathrm{mEq} / 100 \mathrm{~g}-11,933 \mathrm{mEq} / 100 \mathrm{~g}$, kejenuhan basa $11,820 \%-16,040 \%, \mathrm{pH}$ tanah 4,93 - 6,08, C-Organik 2,29 \% - 3,32\%, $\mathrm{P}_{2} \mathrm{O}_{5}$ $4,72 \mathrm{mg} / 100 \mathrm{~g}-25,98 \mathrm{mg} / 100 \mathrm{~g}, \mathrm{~K}_{2} \mathrm{O} 0,139 \mathrm{mg} / 100 \mathrm{~g}-0,154 \mathrm{mg} / 100 \mathrm{~g}$. (2) Tingkat kesesuaian lahan untuk tanaman padi pada daerah penelitian antara lain: kelas $S_{3}$ (sesuai marginal) dengan luas 10,6 $\mathrm{km}^{2}$, dan $\mathrm{N}$ (tidak sesuai) dengan luas $0,4 \mathrm{~km}^{2}$.
\end{abstract}

Kata Kunci : Karakteristik Lahan, Kesuburan Tanah, Kesesuaian Lahan.

\section{ABSTRACT}

The purpose of this research: (1) To know the soil fertility level for paddy farming land in terms of soil physical properties (texture, soil depth and permeability) and soil chemistry (soil $\mathrm{pH}$, C-Organic, cation exchange capacity, saturation bases, $\mathrm{P}_{2} \mathrm{O}_{5}, \mathrm{~K}_{2} \mathrm{O}$ ) in Nagari Talang Babungo, Hiliran Gumanti Sub-district of Solok Regency, (2) Knowing the level of land suitability for paddy farming in Nagari Talang Babungo, Hiliran Gumanti Sub-district.

The method used in this research is survey method with mapping unit used is land unit through overlay map of landform unit with slope map, geology map, land map, and land use map. Sampling by stratified sampling method, with data analysis using matching method and combination method.

The results of this study were: (1) The level of fertility of agricultural land of rice plants in the research area is low $(R)$ whit land characteristics in the study area were: medium soil texture, slightly to fine, soil depth ie 23-> $50 \mathrm{~cm}$, soil permeability is $0.20 \mathrm{~cm} / \mathrm{hour}-27.35$ $\mathrm{cm} / \mathrm{hour}$, cation exchange capacity is $9,448 \mathrm{mEq} / 100 \mathrm{~g}-11,933 \mathrm{mEq} / 100 \mathrm{~g}$, saturation base $11,820 \%-16,040 \%$, soil pH 4,93 - 6,08, C-Organic 2,29\% - 3,32\%, $\mathrm{P}_{2} \mathrm{O}_{5} 4,72 \mathrm{mg} / 100 \mathrm{~g}-25,98$ $\mathrm{mg} / 100 \mathrm{~g}, \mathrm{~K}_{2} \mathrm{O} 0,139 \mathrm{mg} / 100 \mathrm{~g}-0,154 \mathrm{mg} / 100 \mathrm{~g}$. (2) The level of land suitability for rice crops in the research area are: $S_{3}$ class (marginal suit) with area of $10,6 \mathrm{~km}^{2}$, and $N$ (not suitable) with area of $0,4 \mathrm{~km}^{2}$.

Keywords: Land Characteristics, Soil Fertility, Land Suitability.

\footnotetext{
${ }^{1}$ Artikel ini ditulis dari skripsi penulis dengan judul Analisis Kesuburan Tanah Lahan Pertanian Tanaman Padi di Nagari Talang Babungo Kec.Hiliran Gumanti Kab.Solok untuk wisuda periode Maret 2018 dengan

${ }^{2}$ Pembimbing I Drs. Helfia Edial, MT dan Pembimbing II Ratna Wilis, S.Pd, M.P.
} 


\section{Pendahuluan}

Lahan sawah memiliki arti yang sangat penting dalam upaya mempertahankan ketahanan pangan, namun seiring perkembangan zaman, pertambahan penduduk, dan tuntutan ekonomi, eksistensi lahan pangan mulai terusik. Pembangunan pertanian yang telah, sedang, dan akan dilaksanakan pada masa- masa mendatang pada dasarnya memiliki dua tujuan pokok, yaitu untuk meningkatkan produksi baik secara kuantitatif maupun kualitatif serta meningkatkan pendapatan petani. Orientasi peningkatan produksi ditujukan untuk pemenuhan kebutuhan konsumsi dalam negeri terutama untuk beberapa tanaman bahan makanan utama yang memiliki posisi yang sangat strategis seperti beras, jagung, dan kedelai dan untuk memenuhi kebutuhan ekspor terutama dua komunitas perkebunan yang secara tradisional merupakan primadona komoditas ekspor.

Berdasarkan rencana strategisnya (2010-2014), Kementrian Pertanian telah menetapkan lima tujuan pembangunan pertanian, yaitu : (1) Mewujudkan sistem pertanian industrial unggul berkelanjutan yang berbasis sumber daya local; (2) Meningkatkan dan memantapkan swasembada berkelanjutan;

Menumbuh kembangkan ketahanan pangan dan gizi, termasuk diversifikasi pangan; (4) Meningkatkan nilai tambah, daya saing, dan ekspor produk pertanian; (5) Meningkatkan pendapatan dan kesejahteraan petani. Kelima tujuan pembangunan tersebut harus terimplementasi dalam empat target utama, yaitu: (1) pencapaian swasembada dan swasembada berkelanjutan, (2) Peningkatan diversifikasi pangan, (3) peningkatan nilai tambah, daya saing, dan ekspor, dan (4) Peningkatan kesejahteraan petani.

Salah satu permasalahan yang dihadapi bangsa ini dalam kaitannya dengan upaya mempertahankan swasembada beras dan jagung yang telah dicapai pada tahun 2007 dan 2008, serta mengupayakan tercapainya swasembada kedelai, jagung dan daging sapi pada tahun 2014 adalah masih berlangsungnya alih fungsi lahan-lahan pertanian dari areal pertanian tanaman pangan utama ke berbagai penggunaan lain baik yang masih berada dalam lingkup sektor pertanian seperti menjadi areal pertanaman tanaman buah-buahan dan perkebunan yang secara ekonomi lebih menguntungkan maupun kegunaan pada sektor-sektor lain seperti menjadi areal perindustrian, fasilitas umum, dan pemukiman penduduk (Matondang etal. 1992).

Alih fungsi lahan tersebut tidak hanya terjadi di sentra-sentra produksi tanaman pangan terutama di Pulau Jawa, melainkan juga terjadi di luar Pulau Jawa, seperti di Provinsi Sumatera Barat. Pengalihan fungsi lahan dari lahan sawah ke areal penggunaan lain juga terjadi di Nagari Talang Babungo, Kecamatan Hiliran Gumanti Kabupaten Solok.

Pergeseran penggunaan lahan tersebut dipicu karena fungsi sawah sudah tidak optimal, misalnya karena 
telah terjadi degradasi mutu tanah atau berkurangnya tingkat kesuburan tanah sehingga usaha tani tidak dapat berkembang dengan baik. Tingkat kesuburan tanah sawah yang rendah umumnya ditandai dengan kandungan bahan organik dan hara nitrogen yang rendah. Kesuburan tanah sawah perlu ditingkatkan yaitu dengan pemberian bahan organik berupa kompos, pupuk kandang dan jerami padi, di samping itu bahan organik berfungsi sebagai ameliorant yang dapat memperbaiki jumlah dan aktivitas mikroba dan sumber hara dalam tanah sehingga dapat meningkatkan kualitas tanah (Setyorini, 2006).

Salah satu faktor permasalahan dalam meningkatkan produksi tanaman padi adalah petani pada umumnya masih tergantung pada penggunaan pupuk anorganik. Penggunaan pupuk anorganik yang semakin tinggi berdampak pada laju peningkatan hasil produksi padi yang tidak selaras dengan laju penggunaan pupuk, hal tersebut mencerminkan penurunan efisiensi penggunaan

pupuk dan gangguan terhadap ketersediaan hara dan biota tanah. Dampak dari penggunaan pupuk anorganik menghasilkan peningkatan produktivitas tanaman yang cukup tinggi, namun penggunaan pupuk anorganik dalam jangka yang relatif panjang dapat mengganggu keseimbangan hara, tanah menjadi cepat mengeras, kurang mampu menyimpan air, penipisan unsur mikro seperti $\mathrm{Zn}, \mathrm{Mn}, \mathrm{Cu}$, Mn dan Mo dalam tanah, mempengaruhi aktivitas organisme tanah, dapat menurunkan kualitas pada kesehatan tanaman dan kondisi tanah serta dapat menurunkan produktivitas pertanian padi dalam jangka panjang.

Tabel 1. Hasil Produksi Komoditas Padi Tahun 2014-2016 di Nagari Talang Babunngo

\begin{tabular}{|c|c|c|c|c|}
\hline No & \multirow{2}{*}{ Tahun } & \multicolumn{3}{|c|}{ Komponen } \\
\cline { 3 - 5 } & & $\begin{array}{c}\text { RLT } \\
(\mathrm{Ha})\end{array}$ & $\begin{array}{c}\text { RLP } \\
(\mathrm{Ha})\end{array}$ & $\begin{array}{c}\% \\
\text { Produksi }\end{array}$ \\
\hline 1 & 2014 & 939 & 966 & 102,8 \\
\hline 2 & 2015 & 975 & 995 & 102 \\
\hline 3 & 2016 & 1117 & 1029 & 92 \\
\hline
\end{tabular}

Sumber: Penyuluh Dinas Pertanian

Kecamatan Hiliran Gumanti,Kab.Solok.2017

Berdasarkan uraian diatas, penulis tertarik untuk melakukan penelitian tentang kesuburan tanah lahan pertanian padi di Nagari Talang Babungo, Kecamatan Hiliran Gumanti, Kabupaten Solok dengan judul "Analisis Kesuburan Tanah Lahan Pertanian Tanaman Padi di Nagari Talang Babungo, Kecamatan Hiliran Gumanti, Kabupaten Solok".

\section{Metode Penelitian}

\section{Jenis Penelitian}

Jenis penelitian ini adalah survai lapangan yang merupakan studi yang bersifat kuantitatif yang digunakan untuk meneliti gejala suatu kelompok atau suatu prilaku dan pengungkapan suatu masalah atau keadaan sebagaimana adanya dan mengungkapkan fakta-fakta yang ada.

\section{Bahan dan Alat Penelitian}

a. Bahan Penelitian

1). Peta jenis tanah Nagari Talang babungo skala 1:50.000.

2). Peta geologi Nagari Talang babungo skala 1:50.000. 
3). Peta penggunaan lahan Nagari Talang babungo skala 1:50.000.

4). Peta lereng Nagari Talang babungo skala 1:50.000.

5). Peta bentuklahan Nagari Talang babungo skala 1:50.000.

b. Alat yang Digunakan

1). GPS Essentials

2). Ring sampel tanah

3). Sekop, cangkul, pisau

4). Kantong plastik, karet gelang

5). Alat Tulis

\section{Tahap Penelitian}

a. Tahap Pra Lapangan

1). Pengumpulan dan penyediaan bahan dan alat penelitian.

2). Pengurusan surat izin penelitian ke instansi yang terkait.

3). Membuat peta penelitian diperoleh dari tumpang susun (overlay) peta kelas lereng, peta geologi, peta tanah, peta penggunaan lahan dan peta bentuklahan sehingga didapat peta satuan lahan. Dari satuan lahan ini baru diperoleh peta sampel.

4). Survei awal tempat pengambilan sampel dengan mengambil titik koordinat lapangan kemudiaan dicocokkan dengan peta penelitian

b. Tahap Lapangan
1). Melakukan pengamatan dan pengukuran karakteristik lahan di lapangan.

2). Pengambilan sampel tanah dari setiap satuan lahan untuk dianalisis di laboratorium

c. Tahap Pasca Lapangan

1). Pengolahan data pengukuran lapangan dan data analisis laboratorium yang hasilnya berupa tabel kriteria dan kategori kualitas dari masing-masing sampel penelitian.

2). Pencocokan antara hasil penelitian dengan persyaratan tanaman padi untuk memperoleh kesesuaian lahan tanaman padi.

3). Penulisan laporan

\section{Teknik dan Cara Penarikan Sampel}

Pengambilan sampel pada daerah penelitian diambil pada satuan lahan yang terdapat bagian penggunaan lahan sawah yakni terdapat 4 titik sampel, yang ditentukan dengan teknik sampel bertingkat (Stratified Sampling) (Roziana, 2003), sampel tanahnya diambil secara komposit pada kedalaman $0-50 \mathrm{~cm}$.

\section{Peta Titik Sampel Penelitian dapat dilihat pada Gambar 1 berikut:}

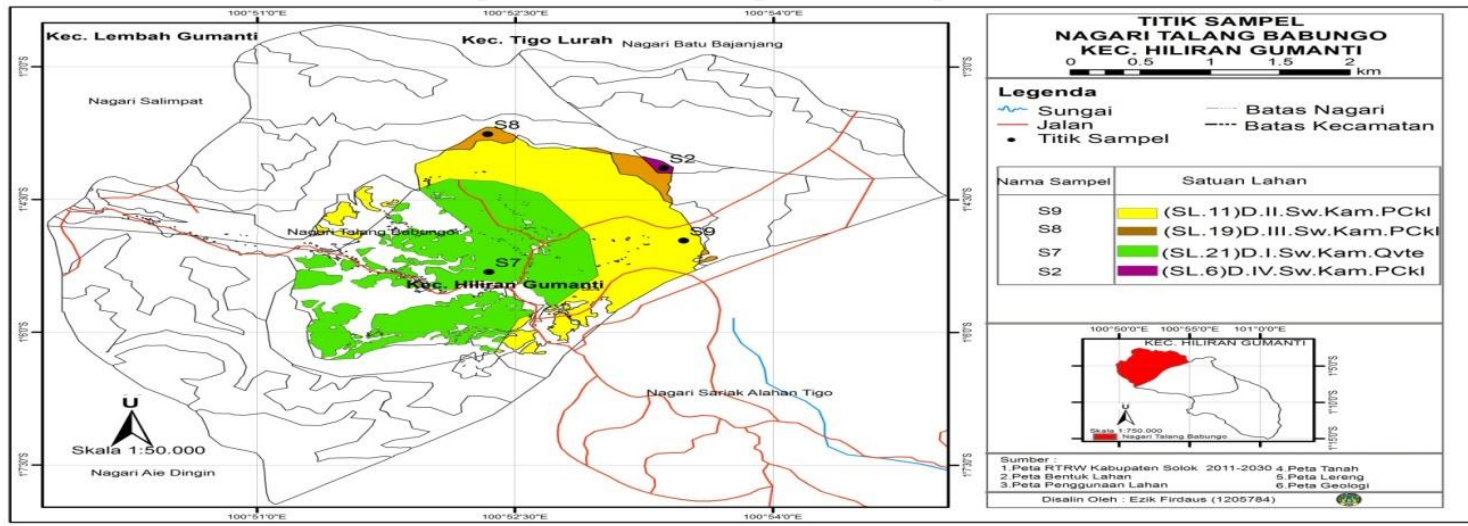

Gambar 1. Peta Titik Sampel Penelitian 


\section{Jenis Data}

Tabel 2. Data Penelitian

\begin{tabular}{|c|l|l|}
\hline $\begin{array}{c}\text { N } \\
0\end{array}$ & \multicolumn{1}{|c|}{ Data } & \multicolumn{1}{c|}{$\begin{array}{c}\text { Sumber } \\
\text { Data }\end{array}$} \\
\hline 1 & Peta Jenis Tanah & RTRW Kab. Solok \\
\hline 2 & Peta Geologi & RTRW Kab. Solok \\
\hline 3 & Peta Lereng & $\begin{array}{l}\text { RTRW Kab. Solok } \\
\text { SRTM dari USGS }\end{array}$ \\
\hline 4 & Peta bentuklahan & RTRW Kab. Solok \\
\hline 4 & Peta Penggunaan Lahan & $\begin{array}{l}\text { RTRW Kab. Solok } \\
\text { Citra QuidBird }\end{array}$ \\
\hline 5 & Data Iklim & $\begin{array}{l}\text { BPTP dan Balitbu Kab. } \\
\text { Solok }\end{array}$ \\
\hline 7 & Media Perakaran & $\begin{array}{l}\text { Pengamatan, pengukuran } \\
\text { Lapangan }\end{array}$ \\
\hline 8 & Retensi Hara & Analisis Laboratorium \\
\hline
\end{tabular}

\section{Teknik Pengumpulan Data}

Pengumpulan data kesuburan tanah dan karakteristik lahan untuk kesesuaian lahan untuk tanaman padi pada daerah penelitian dengan cara pengamatan dan pengukuran di lapangan serta uji laboratorium.

\section{Analisis Data}

\section{a. Kriteria Kesuburan Tanah}

Analisis data dalam penelitian ini menggunakan analisis kombinasi kesuburan kimia tanah, kombinasi kesuburan fisik tanah dan tingkat kesuburan tanah total.

\section{b. Karakteristik Lahan}

Karakteristik lahan yang diteliti untuk tanaman padi pada daerah penelitian disesuaikan dengan karakteristik yang dibutuhkan dalam syarat tumbuh tanaman padi yaitu temperatur rata-rata tahunan, ketersedian air (curah hujan rata-rata tahunan), media perakaran (tekstur tanah, kedalaman tanah, permeabilitas tanah), retensi hara (KTK tanah, kejenuhan basa, $\mathrm{pH}, \mathrm{C}$-Organik, $\mathrm{P}_{2} \mathrm{O}_{5}$, $\mathrm{K}_{2} \mathrm{O}$ ).

Tabel 3.Kriteria Kesesuaian Lahan yang telah diusahakan untuk Komoditas Tanaman Pangan Padi (Oryza sativa).

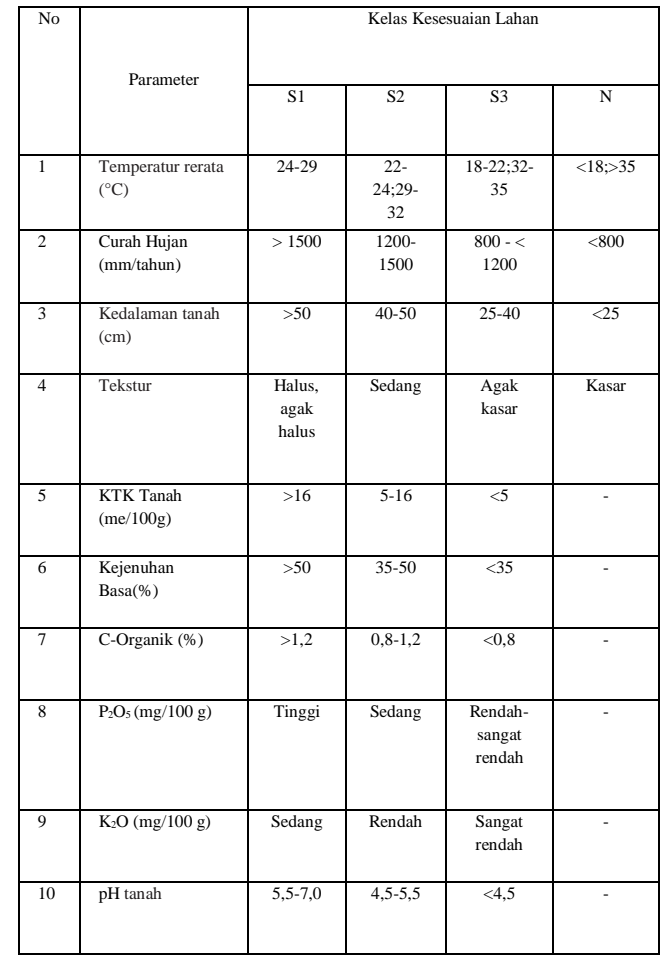

*)S1:sangat sesuai; S2:cukup sesuai; S3:sesuai marginal; N:tidak sesuai;(-)tidak diperhitungkan. Sumber: PERATURAN MENTERI PERTANIAN NOMOR 79/Permentan/OT.140/8/2013.dimodifikasi

\section{c. Kesesuaian Lahan}

Kesesuaian lahan adalah tingkat kecocokan suatu bidang lahan untuk penggunaan tertentu. Teknik analisis yang dilakukan adalah dengan cara mencocokan (matching) antara karakteristik lahan sebagai parameter pada setiap satuan lahan dengan persyaratan tumbuh tanaman padi.

Tingkat kesesuaian lahan ditentukan oleh faktor pembatas terberat, faktor pembatas tersebut dapat 
terdiri dari satu atau lebih tergantung dari karakteristik lahannya.

\section{Hasil dan Pembahasan}

\section{Karakteristik Lahan dan Kriteria Kesuburan Tanah di Daerah Penelitian}

\section{a. Suhu/Temperatur}

Temperatur merupakan faktor utama yang mempengaruhi tahap perkembangan tanaman padi mulai dari periode penanaman sampai dengan panen. Data temperatur rata-rata tahunan (2013 - 2015) diperoleh dari stasiun pengamat Balitbu Tropika Sumani, dengan temperatur rata-rata tahun pada daerah penelitian yaitu 22 $30{ }^{\circ} \mathrm{C}$. Temperatur yang dikehendaki tanaman padi yaitu $24-29{ }^{\circ} \mathrm{C}$. Temperatur di daerah penelitian tergolong sangat sesuai $\left(\mathrm{S}_{1}\right)$ untuk tanaman padi.

\section{b. Ketersediaan Air}

Data curah hujan 5 tahun terakhir (2011 - 2015) diperoleh dari stasiun penangkar hujan yaitu BPTP Sukarami, dengan curah hujan rata-rata tahunan pada daerah penelitian adalah 2.404 $3.180 \mathrm{~mm} / \mathrm{th}$. Curah hujan yang dikehendaki tanaman padi adalah berkisar $>1500 \mathrm{~mm} / \mathrm{th}$. Curah hujan di daerah penelitian tergolong sangat sesuai $\left(S_{1}\right)$ untuk tanaman padi.

\section{c. Media perakaran}

Media perakaran merupakan tempat tinggal akar tanaman. Sebagai tempat tinggal yang baik, media perakaran harus dapat mendukung pertumbuhan dan kehidupan tanaman.
Kesuburan fisik tanah dapat dilihat dari permeabilitas, tekstur tanah dan kedalaman efektif tanah.

1). Tekstur tanah

Tekstur tanah pada daerah penelitian untuk kesuburan fisik tanah dikategorikan sedang serta kesesuaian lahan untuk tanaman padi dikategorikan halus sampai agak halus yang terdiri dari geluh berpasir dan geluh yaitu sangat sesuai $\left(S_{1}\right)$ untuk tanaman padi terdapat pada 3 satuan lahan antara lain; (SL.6)D.IV.Sw.Kam.PCkl,

(SL.19)D.III.Sw.Kam.PCkl,

(SL.11)D.II.Sw.Kam.PCkl, dan rendah pada 1 satuan lahan yaitu; (SL.21)D.I.Sw.Kam.Qvte.

2). Permeabilitas Tanah

Permeabilitas tanah pada daerah penelitian terdapat 2 kategori berdasarkan kriteria kesuburan fisik tanah yakni dikategorikan rendah termasuk pada kedalaman tanah sangat dangkal $(<25 \mathrm{~cm})$ terdapat pada satuan lahan (SL.6)D.IV.Sw.Kam.PCkl dan dikategorikan sedang dan tinggi terdapat pada satuan lahan (SL.19)D.III.Sw.Kam.PCkl dan (SL.11)D.II.Sw.Kam.PCkl dan tinggi pada satuan lahan (SL.21)D1.I.Sw.Kam.Qvte.

3). Kedalaman tanah

Kedalaman tanah berkaitan dengan sejauh mana akar dapat menembus tanah untuk menyerap air dan unsur hara bagi tanaman. Kedalaman tanah untuk tanaman padi $>50 \mathrm{~cm}$.

Kedalaman tanah di lapangan berkisar antara $<25->50 \mathrm{~cm}$, untuk kesuburan tanah tergolong rendah sedang dan tinggi dan untuk kesesuaian lahan tergolong kelas Sangat Sesuai 
$\left(\mathrm{S}_{1}\right)$, Sesuai Marginal $\left(\mathrm{S}_{3}\right)$ dan Tidak Sesuai $(\mathrm{N})$.

\section{d. Retensi Hara}

Retensi hara merupakan kemampuan untuk memegang dan melepaskan hara, dalam retensi hara ini dipengaruhi oleh kapasitas tukar kation (KTK), kejenuhan basa tanah, $\mathrm{pH}$ tanah, dan $\mathrm{C}$ Organik, $\mathrm{P}_{2} \mathrm{O}_{5}, \mathrm{~K}_{2} \mathrm{O}$.

1). KTK Tanah

Kapasitas pertukaran kation berkaitan dengan banyaknya kation yang dapat diserap oleh tanah. Tanaman padi menghendaki KTK tanah >16 $\mathrm{mEq} / 100 \mathrm{~g}$. KTK tanah pada daerah penelitian yaitu 5-16 $\mathrm{mEq} / 100 \mathrm{~g}$ dikategorikan rendah untuk tingkat kesuburan tanah terdapat pada satuan lahan (SL.6)D.IV.Sw.Kam.PCkl, (SL.19)D.III.Sw.Kam.PCkl,

(SL.21)D.I.Sw.Kam.Qvte dan satuan lahan (SL.11)D.II.Sw.Kam.PCk1 sedangkan untuk kesesuaian lahan dikategorikan sedang / cukup sesuai $\left(\mathrm{S}_{2}\right)$.

2). Kejenuhan Basa

Kesuburan tanah akan meningkat dengan meningkatnya nilai kejenuhan basa pada tanah. Tanaman padi menghendaki tanah dengan kejenuhan basa $>50 \%$. Kejenuhan basa tanah pada daerah penelitian $<35 \%$ yaitu 11,82 $16.04 \%$ dikategorikan rendah untuk kesuburan tanah dan untuk kesesuaian lahan di kategorikan sesuai marginal (S3). yaitu terdapat pada satuan lahan (SL.6)D.IV.Sw.Kam.PCkl,

(SL.19)D.III.Sw.Kam.PCkl,

(SL.21)D.I.Sw.Kam.Qvte, dan satuan lahan (SL.11)D.II.Sw.Kam.PCkl.

3). $\mathrm{pH}$ tanah
$\mathrm{pH}$ tanah yang sesuai untuk tanaman padi berkisar antara 5,5 - 7,0. $\mathrm{pH}$ tanah pada daerah penelitian bersifat asam dengan skala pH 4,93-6,08 di kategorikan rendah dan sedang untuk tingkat kesuburan tanah yaitu terdapat pada satuan lahan (SL.11)D.II.Sw.Kam.PCkl dan rendah (r) pada satuan lahan (SL.6)D.IV.Sw.Kam.PCkl, (Sl.19)D.III.Sw.Kam.PCkl dan (SL.21)D.I.Sw.Kam.Qvte. Untuk kesesuaian lahan di kategorikan sangat sesuai (S1) dan cukup sesuai (S2).

4). C-Organik

Tanaman padi menghendaki tanah dengan C-Organik $>1,2 \%$. Kandungan C-Organik pada tanah di daerah penelitian yakni 2,29-3,32\% dikategorikan sedang sampai tinggi untuk tingkat kesuburan tanah dan untuk kesesuiaian lahan dikategorikan tinggi yaitu $>1,2 \%$ sangat sesuai (S1). Pada daerah penelitian kandungan $\mathrm{C}$ Organik untuk kesuburan kimia tanah tergolong tinggi $(\mathrm{t})$ terdapat pada satuan lahan (SL.6)D.IV.Sw.Kam.PCkl dan sedang (s) pada satuan lahan (SL.19)D.III.Sw.Kam.PCkl,

(SL.21)D.I.Sw.Kam.Qvte dan (SL.11)D.II.Sw.Kam.PCkl. Tanaman padi membutuhkan kandungan $\mathrm{C}$ organik tanah yang tinggi yaitu $>1,2 \%$, dimana kesuburan tanah sangat bergantung pada kandungan organik dalam tanah, semakin tinggi kadar COrganik pada tanah semakin subur tanah tersebut.

5). Pospor $\left(\mathrm{P}_{2} \mathrm{O}_{5}\right)$

Pada daerah penelitian kandungan $\mathrm{P}_{2} \mathrm{O}_{5}$ tergolong sangat rendah yaitu $<15$ $\mathrm{mg} / 100 \mathrm{~g}$ yaitu terdapat pada satuan 
lahan

(SL.19)D.III.Sw.Kam.PCkl, (SL.21)D.I.Sw.Kam.Qvte, dan satuan lahan (SL.11)D.II.Sw.Kam.PCkl dan sedang yaitu $25,98 \mathrm{mg} / 100 \mathrm{~g}$ yaitu terdapat pada satuan lahan (SL.6)D.IV.Sw.Kam.PCkl. Tanaman padi membutuhkan kandungan $\mathrm{P}_{2} \mathrm{O}_{5}$ pada tanah yaitu $41-60 \mathrm{mg} / 100 \mathrm{~g}$.

6). Kalium $\left(\mathrm{K}_{2} \mathrm{O}\right)$

Pada daerah penelitian untuk tingkat kesuburan tanah kandungan $\mathrm{K}_{2} \mathrm{O}$ tergolong rendah yaitu $<20 \mathrm{mg} / 100 \mathrm{~g}$ terdapat pada satuan lahan (SL.6)D.IV.Sw.Kam.PCkl, (SL.19)D.III.Sw.Kam.PCkl,

(SL.21)D.I.Sw.Kam.Qvte, dan satuan lahan (SL.11)D.II.Sw.Kam.PCkl. Tanaman padi membutuhkan kandungan $\mathrm{K}_{2} \mathrm{O}$ pada tanah yaitu $21-40$ $\mathrm{mg} / 100 \mathrm{~g}$.

\section{Kesuburan Tanah Tanaman Padi}

\section{di Daerah Penelitian}

a. Status kesuburan kimia tanah

Tingkat kesuburan kimia tanah tanaman padi di nagari Talang Babungo tergolong rendah $(r)$ yaitu terdapat pada

Hasil kesuburan tanah lahan pertanian tanaman padi yaitu tergolong rendah, dapat dilihat pada Gambar 2 berikut.

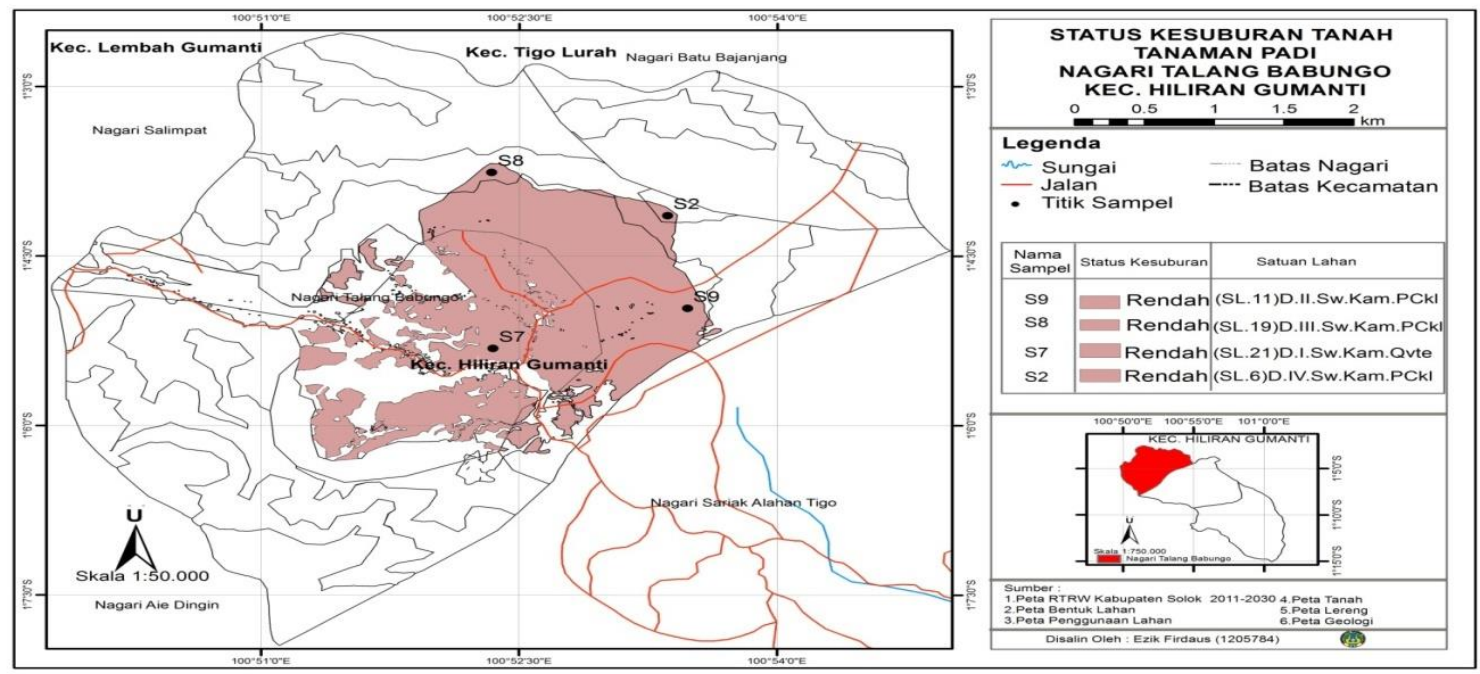

Gambar 2. Peta Tingkat Kesuburan Tanah Lahan Pertanian

Tanaman Padi di Nagari Talang Babungo satuan lahan (SL.6)D.IV.Sw.Kam.PCkl, (SL.19)D.III.Sw.Kam.PCkl,

(SL.21)D.I.Sw.Kam.Qvte, dan satuan lahan (SL.11)D.II.Sw.Kam.Qvte.

b. Status kesuburan fisik tanah

Tingkat kesuburan fisik tanah tanaman padi di nagari Talang Babungo tergolong sedang yaitu terdapat pada satuan lahan (SL.6)D.IV.Sw.Kam.PCkl, (SL.19)D.III.Sw.Kam.PCkl,

(SL.11)D.II.Sw.Kam.PCkl, dan rendah terdapat pada satuan lahan (SL.21)D.I.Sw.Kam.Qvte.

c. Status kesuburan tanah total

Tingkat kesuburan tanah total tanaman padi di nagari Talang Babungo tergolong rendah. Untuk lebih jelas dapat dilihat pada peta kesuburan tanah 


\section{Kesesuaian Lahan untuk Tanaman Padi di Daerah Penelitian}

Penilaian kesesuaian lahan untuk tanaman padi dilakukan dengan metode matching, yaitu dengan membandingkan karakteristik lahan yang telah didapatkan dari hasil penelitian di lapangan dengan persyaratan tumbuh untuk tanaman padi. Maka didapatkan kelas kesesuaian lahan untuk tanaman padi di daerah penelitian.

Kesesuaian lahan adalah kesesuaian dari suatu bidang lahan untuk tujuan penggunaan atau komoditas spesifik seperti padi. Berdasarkan metode matching (mencocokan) antara karakteristik lahan sebagai parameter pada setiap satuan lahan pada 4 sampel penelitian dengan persyaratan tumbuh tanaman padi, maka diperoleh kelas kesesuaian lahan $S_{1}$ (sangat sesuai), $\mathrm{S}_{2}$ (cukup sesuai), $\mathrm{S}_{3}$ (sesuai marginal) dan $\mathrm{N}$ (tidak sesuai). Tingkat kesesuaian lahan ditentukan oleh faktor pembatas terberat, faktor pembatas tersebut dapat terdiri dari satu atau lebih tergantung dari karakteristik lahannya.

a. Kesesuaian Lahan Untuk Tanaman

Padi di Nagari Talang Babungo

Sampel S2

(SL.6)D.IV.Sw.Kam.PCkl.

Dilihat hasil pencocokan

karakteristik lahan dengan kriteria

kesesuaian lahan untuk komoditas

tanaman padi berdasarkan

PERATURAN MENTERI

PERTANIAN NOMOR

79/Permentan/OT.140/8/2013, maka

kelas kesesuaian lahan untuk tanaman padi pada sampel S2 satuan lahan (SL.6)D.IV.Sw.Kam.PCkl adalah tidak sesuai (N rc) dimana faktor pembatasnya adalah media perakaran (rc) berupa kedalaman tanah.

b. Kesesuaian Lahan Untuk Tanaman Padi di Nagari Talang Babungo

Sampel S8 (SL.19)

D.III.Sw.Kam.PCkl.

Hasil pencocokan karakteristik lahan dengan kriteria kesesuaian lahan untuk komoditas tanaman padi berdasarkan PERATURAN MENTERI PERTANIAN NOMOR

79/Permentan/OT.140/8/2013, maka kelas kesesuaian lahan untuk tanaman padi pada sampel S8 satuan lahan (SL.19)D.III.Sw.Kam.PCkl adalah sesuai marginal / S3. Faktor pembatasnya adalah media perakaran (rc) berupa kedalaman tanah, dan retensi hara (nr) berupa kejenuhan basa dan $\mathrm{P}_{2} \mathrm{O}_{5}$.

c. Kesesuaian Lahan Untuk Tanaman Padi di Nagari Talang Babungo Sampel S7 (S1.21)D.I.Sw.Kam.Qvte.

Hasil pencocokan karakteristik lahan dengan kriteria kesesuaian lahan untuk komoditas tanaman padi berdasarkan PERATURAN MENTERI PERTANIAN NOMOR 79/Permentan/OT.140/8/2013, maka kelas kesesuaian lahan untuk tanaman padi pada sampel S7 satuan lahan (SL.21)D.I.Sw.Kam.Qvte adalah sesuai marginal / S3. Faktor pembatasnya adalah retensi hara (nr) berupa kejenuhan basa dan $\mathrm{P}_{2} \mathrm{O}_{5}$. 
d. Kesesuaian Lahan Untuk Tanaman Padi di Nagari Talang Babungo Sampel S9

(SL.11)D.II.Sw.Kam.PCkl.

Hasil pencocokan karakteristik lahan dengan kriteria kesesuaian lahan untuk komoditas tanaman padi berdasarkan PERATURAN MENTERI PERTANIAN NOMOR 79/Permentan/OT.140/8/2013, maka kelas kesesuaian lahan untuk tanaman padi pada sampel S9 satuan lahan (SL.11)D.II.Sw.Kam.PCkl adalah sesuai marginal / S3. Faktor pembatasnya adalah media perakaran (rc) berupa kedalaman tanah dan retensi hara (nr) berupa kejenuhan basa dan $\mathrm{P}_{2} \mathrm{O}_{5}$.

Berdasarkan hasil pengolahan data di atas dapat disimpulkan tingkat kesesuaian lahan untuk tanaman padi di nagari Talang Babungo sebagai berikut:

\section{Kelas Kesesuaian Lahan}

Kelas kesesuaian lahan untuk tanaman padi di nagari Talang Babungo antara lain: a. Kelas $\mathrm{S}_{3}$ (sesuai marginal) yaitu terdapat pada sampel S8, S7 dan S9 dengan satuan lahan (SL.19)D.III.Sw.Kam.PCkl, (SL.21)D.I.Sw.Kam.Qvte dan (SL.11)D.II.Sw.Kam.PCkl dengan luas keseluruhan yaitu $10.6 \mathrm{Km}^{2}$ dari $11 \mathrm{Km}^{2}$ luas penggunaan lahan sawah atau pertanian tanaman padi di nagari Talang Babungo.

b. Kelas $\mathrm{N}$ (tidak sesuai) yaitu terdapat pada sampel S2 dengan satuan lahan (SL.6)D.IV.Sw.Kam.PCkl dengan luas keseluruhan yaitu $0.4 \mathrm{Km}^{2}$ dari 11 $\mathrm{Km}^{2}$ luas penggunaan lahan sawah atau lahan pertanian tanaman padi di nagari Talang Babungo.

Hasil kesesuaian lahan untuk tanaman padi antara lain tingkat kelas, terdiri kelas $\mathrm{S}_{3}$ (Sesuai Marginal) dengan luas 10,6 Km2, dan kelas $\mathrm{N}$ (Tidak Sesuai) dengan luas 0,4 Km2,

Persebaran kelas kesesuaian lahan untuk tanaman padi di nagari Talang Babungo dapat dilihat pada Gambar 3 berikut.

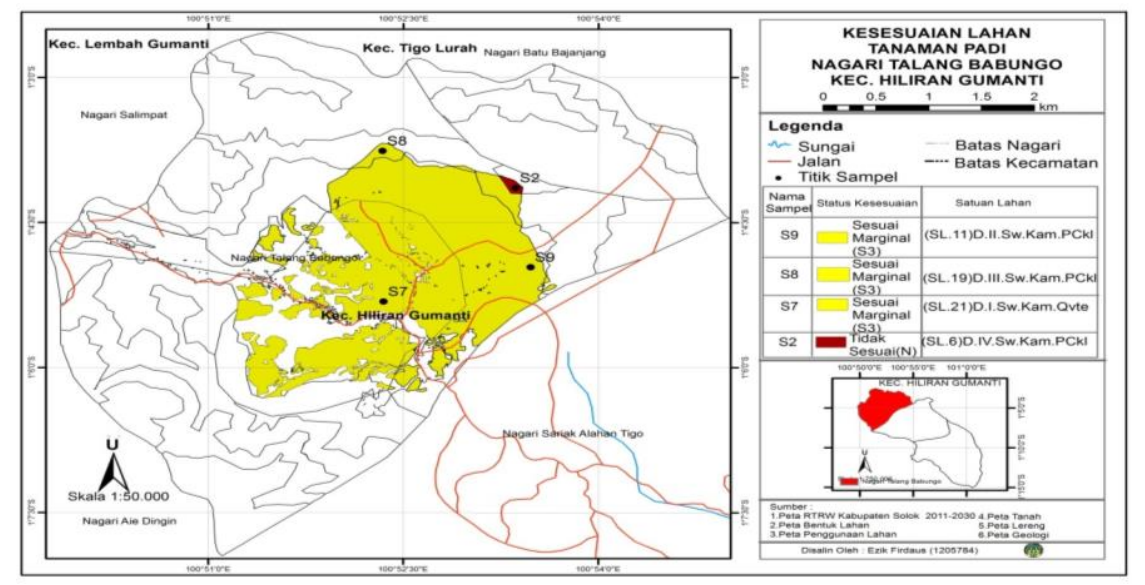




\section{Penutup}

\section{Kesimpulan}

a. Kesuburan tanah tanaman padi pada daerah penelitian yang di lihat dari kesuburan fisik tanah dan kesuburan kimia tanah antara lain; permeabilitas tanah yaitu sedang dan lambat-sangat lambat/cepatsangat cepat, tekstur tanah yaitu halus sampai agak halus (geluh,geluh berlempung, lempung berpasir, lempung berdebu dan lempung berpasir), kedalaman tanah yaitu $30 \mathrm{~cm}$ sampai $>50 \mathrm{~cm}$, KTK tanah yaitu 9,448 me/100g sampai 11,933 me/100g, kejenuhan basa yaitu $11,820 \%$ sampai $16,040 \%, \mathrm{pH}$ tanah yaitu 4,93 sampai 6,08, C-Organik yaitu $2,29 \%$ sampai $3,32 \%, \mathrm{P}_{2} \mathrm{O}_{5}$ yaitu $4,72 \mathrm{mg} / 100 \mathrm{~g}$ sampai 25,98 $\mathrm{mg} / 100 \mathrm{~g}$ dan $\mathrm{K}_{2} \mathrm{O}$ yaitu 0,139 $\mathrm{mg} / 100 \mathrm{~g}$ sampai $0,154 \mathrm{mg} / 100 \mathrm{~g}$. Karakteristik lahan untuk tanaman padi pada daerah penelitian antara lain; temperatur rata-rata tahunan yaitu 22-30 ${ }^{\circ} \mathrm{C}$, curah hujan ratarata tahunan yaitu 2.404-3.180 $\mathrm{mm} /$ th. Tingkat kesuburan tanah tanaman padi di Nagari Talang Babungo yaitu tergolong rendah (r) di dapat dari hasil kombinasi kesuburan fisik tanah dengan kesuburuan kimia tanah yang menghasilkan kesuburan tanah total.

b. Tingkat kesesuaian lahan untuk tanaman padi pada daerah penelitian antara lain; tingkat kelas, yaitu kelas sesuai marginal (S3) dengan luas keseluruhan yaitu 10,6 $\mathrm{km}^{2}$ dari $11 \mathrm{~km}^{2}$ luas lahan pertanian tanaman padi atau penggunaan lahan sawah nagari Talang Babungo, dan kelas tidak sesuai (N) yaitu terdapat pada sampel S2 dengan luas keseluruhan yaitu $0,4 \mathrm{~km}^{2}$ dari $11 \mathrm{~km}^{2}$ luas lahan pertanian tanaman padi atau penggunaan lahan sawah di nagari Talang Babungo.

\section{Saran}

a. Para petani yang akan mengembangkan tanaman padi dapat melakukan pemilihan lahan yang sesuai agar hasil perolehan panen padi dapat maksimal.

b. Berdasarkan faktor-faktor penghambat yang terdapat di daerah penelitian, seharusnya para petani melakukan perbaikan pada lahan-lahan untuk tanaman padi agar memporeh hasil panen padi yang maksimal.

c. Untuk kedalaman tanah umumnya tidak dapat dilakukan perbaikan, kecuali pada lapisan pedas lunak dan tipis dengan membongkarnya saat pengolahan tanah.

d. Untuk kejenuhan basa dilakukan perbaikan dengan cara pengapuran dan penambahan bahan organik.

e. Untuk dinas terkait, dalam ini Dinas Pertanian lebih memperhatikan tentang pentingnya arti kesuburan dan kesesuaian lahan ini, tidak hanya untuk tanaman padi tapi untuk tanaman lainnya agar petani dapat memperoleh hasil panen yang maksimal dan tidak mengecewakan. 


\section{DAFTAR PUSTAKA}

[Ditjenbun] Direktorat Jenderal

Perkebunan. 2010. Rencana

Strategis Pembangunan

Perkebunan 2010-2014,

Kementerian Pertanian RI

Matondang S, R Situmorang, dan SMH

Tampubolon. 1992. Prospek

Sumbangan Intensifikasi Padi di

Daerah Pasang Surut dalam

Usaha Mempertahankan

Swasembada Beras. Dalam

Risalah Pertemuan Nasional

Pengembangan Pertanian Lahan

Rawa Pasang Surut dan Lebak,

Cisarua 3-4 Maret 1992. Bogor:

Pusat Penelitian dan

Pengembangan Pertania

Nasution, Rozaini. 2003. "Teknik

Sampling”. Digitized by USU

Digital Library. Fakultas

Kesehatan Masyarakat

Universitas Sumatera Utara.

Peraturan Menteri Pertanian Nomor

79/Permentan/OT.140/8/2013.

Pedoman Kesesuaian Lahan

Pada Komoditas Tanaman

Pangan. Jakarta. Menteri

Pertanian Republik Indonesia.

Setyorini, D., R. Saraswati, dan E. K. Anwar. 2006. Kompos. Dalam

Agus, F., R. D. M.

Simanungkalit, D. A.

Suriadikarta, R. Saraswati dan

W. Hartati (ed.). Pupuk Organik dan Pupuk Hayati. Balai Besar

Litbang Sumberdaya Lahan

Pertanian. Badan Penelitian dan

Pengembangan Pertanian.

Departemen Pertanian.

BBLPSLP. Bogor 